\title{
Vocal and Vehement: Understanding Parents' Aversion to Standards-Based Grading
}

\author{
Anne Frankin ${ }^{1}$, Tom Buckmiller ${ }^{1}$, Jerrid Kruse ${ }^{1}$ \\ ${ }^{1}$ School of Education, Drake University, Des Moines, Iowa, USA \\ Correspondence: Tom Buckmiller, School of Education, Drake University, Des Moines, IA, USA, 50311
}

Received: September 26, 2016

Accepted: October 13, 2016

Available online: October 14, 2016

doi:10.11114/ijsss.v4i11.1923

URL: http://dx.doi.org/10.11114/ijsss.v4i11.1923

\begin{abstract}
The implementation of a standards based grading (SBG) system has proven to be difficult even in school districts that tend to be progressive in their educational approaches. Parents are often resistant to the change in grading systems and seem to be a significant barrier to a school's move to SBG. Researchers in this qualitative study went directly to the parents who most vocally and vehemently opposed the new assessment system and sought to understand their perceptions. Data from these interviews produced five themes: Confidence in the known, dislike for the unknown; poor communication leading to disappointment; confusion from lack of clarity; and frustration due to perceived outcomes. Data from this study indicate that school leaders ought to consider reframing grading reform and better align it with Dweck's growth-mindset model and create a process that is less about enticing students with the currency of grades and more about helping students' learning dispositions that would enable success in college and career. Further, in addition to vigilant communication, school leaders need to plan high quality professional development to clarify and refine the purpose of grading and align practices with that purpose.
\end{abstract}

Keywords: Standards based grading (SBG), growth-mindset, assessment, grading

\section{Introduction}

Westside middle school $\left(6-8^{\text {th }}\right.$ grades), situated in a progressive and growing Midwest suburban district, began the process of transitioning to a standards-based grading (SGB) system four years ago. With an understanding of best practice and current research, the school began using SBG in the sixth grade during year one of the transition. The following year SBG was implemented at both the $6^{\text {th }}$ and $7^{\text {th }}$ grades. The plan was to add SBG to the $8^{\text {th }}$ grade during the third year. But a funny thing happened on the way to full implementation.

While a great majority of the school's administrators and teachers, and even students, bought into SBG, there were a strong, and vocal, group of parents who did not. This opposition was a barrier and the implementation was stalled (and continues to be stalled) at grades 6 and 7. Teachers and administrators found themselves face-to-face with parents who passionately disagreed with the SBG model and who were resistant to the change in grading practices.

Successful implementation, even of a highly defensible program or initiative, takes thoughtful, transparent, strategic and systemic thinking. Working towards a successful implementation effort takes an informed anticipation of, and a thoughtful response to, the needs and concerns of the parents who oppose to such an initiative. Researchers in this qualitative study went directly to the parents who most vocally and vehemently opposed the new assessment system and sought to understand their perceptions. This study reports the findings with the hopes of assisting school leaders in disentangling one of the most significant barriers to SBG implementation.

\subsection{Statement of the Problem}

As Peters and Buckmiller (2014) concluded parents are often resistant to the change in grading systems and seem to be a significant barrier to a school's move to SBG. The current grading system is over a century old and has, improbably, been conducted to date without a meaningful body of research to support it (Peters \& Buckmiller, 2014). Typically school shareholders have such unblinking trust in what grades convey that they have largely gone without challenge and are highly resistant to change (Marzano, 2000) Thus, SBG and other alternative grading methods are thus still seen as contentious topics within entire school communities, especially amongst parents (Brookhart, 2011; Reeves, 2011). If the purpose of a grade is to communicate progress to students and parents, then these stakeholders must be participants in 
the research conversation. To that end, there is more learn about why parents are resistant to changing an antiquated grading system that has no research supporting student achievement or growth.

Reeves (2011) and Brookhart (2011) highlight the fact that sometimes simply starting the conversation about grading reform can be touchy for parents without teacher preparation. Barriers that are detrimental to the learning process will arise when parents are not fully on board with the implementation of a new grading model and open dialogue does not occur. Barriers to successful implementation will further impede communication and take the focus away from student learning and achievement. In order to remove these barriers and successfully shift toward a different way of reporting and assessment, the parent's voice must be heard.

\subsection{Purpose of the Study}

The purpose of this study was to describe parents' experience of interpreting standards-based grades in order to identify potential barriers to successful implementation of the grading system. This study focused on the perceptions of parents who have expressed their discontent to a school official. Understanding the experience and perceptions of these parents may allow school district leaders to better understand and anticipate certain barriers in navigating a new grading system and gain insight into their potential resistance.

\subsection{Research Question}

The research questions of this study were: What are the experiences of parents, who have expressed frustration with SBG, in interpreting SBG? Sub-questions were: How do parents feel about the shift from traditional to standards-based grades (emotions)? and what do parents find helpful or problematic about interpreting standards-based grades?

\subsection{Limitations}

Every research study has its unique limitations. The units of analysis for this study were parents who have specifically expressed resistance to SBG. Therefore, this study is not able to generalize the experience of all parents, but possibly a transference to those struggling with the implementation of SBG. Similarly, only parents without formal teacher preparation or training were selected rather than those familiar with alternative grading practices.

\subsection{Literature Review}

While initial discussions of grade reform began subtly with analyses such as Popham and Husek's (1969) comparison of norm-referenced versus criterion-referenced assessments, it has progressed to contesting the entire method with which grades are reported. Stiggins (1991) claimed that the US is entering an entirely new era of assessment. Given the constant changes in the US educational system, current education reform continues to call into question the purpose of grades as the educational system is beginning to acknowledge the fact that traditional grading is flawed. The current trend toward differentiation and student ownership stresses the need for assessment for learning, rather than assessment of learning, which can be achieved through alternative grading practices (Scriffiny, 2008; R. Stiggins, 2009; Tomlinson, 2001).

Educators who are critical of traditional grading methods have cited multiple flaws in the traditional grading practices. One concern is that incorporating zeros for missing assignments mathematically skews the grade. Typically, there is a ten percent range for an $\mathrm{A}, \mathrm{B}, \mathrm{C}$, or $\mathrm{D}$, and a fifty percent range for an $\mathrm{F}$, which creates a disproportionate average of the final grade. To counter this, alternative grading practices suggest assigning a fifty percent instead of a zero (Connor \& Wormeli, 2011; Reeves, 2004; Wormeli, 2006). This practice mediates the mathematical inaccuracy of averaging a zero by maintaining the ten percent difference in letter grades. While some educators argue this is giving points for work not done, Reeves (2004) wrote that an F is an F whether it is zero percent or fifty percent. Omitting zeros seem to assist student's capability to recover from an average skewed by an abnormally low grade and thus their final grade may be a more accurate representation of their mastery level.

It may be unrealistic to expect individual students to learn material at the exact same rate or be able to show mastery at the exact same time as their peers. Rather than using grades to compare students to one another, grade reform efforts encourage grades as a means to compare students to themselves, showing growth in their learning over time (Guskey, 2011). Wormeli (2011) proposed allowing "redos" and retakes, a practice often ignored in traditional grading. He argued retakes are necessary in order for the grade to truly capture student growth at the time of reporting rather than a single moment in the past. According to Marzano and Heflebower (2011), if the purpose of a grade is to report mastery, then educators must look for evidence of learning over time with multiple opportunities for updates.

Traditional grades also often are influenced by behavioral factors such as attendance, participation, effort, and late work influence an academic grade and provide a distorted and inaccurate communication of student learning. If the purpose of the grade is to communicate academic achievement, then behavior should not be included in the grade (Connor \& Wormeli, 2011; Guskey, 1994, 2011; Scott, 2005). This is not to say that behavior should not be documented and reported 
to parents and students. Rather, behavior should be documented separately, possibly as a separate grade alongside the academic grade, or by adding a behavior rubric to the report card.

\subsubsection{Standards-Based Grading}

SBG is a defensible system for fair and accurate assessment of student work. In this system students are entitled to receive accurate and timely feedback on their strengths, deficiencies, and actions that can be taken to achieve learning goals. Research supports this type of feedback; Hattie (1992), in a review of studies on learning and instruction, reported that providing students with specific information about their standing in terms of particular objectives significantly increased their achievement. O'Connor (1999) identified strategies that are increasingly being used to better align grading and assessment with standards:

- Incorporating more formative work that is not included in final grades (making every assignment summative can inhibit students from learning, taking risks or being creative, as they become overly focused on accumulating points).

- Updating grades frequently: Learning is a continuous process; and the quality of learning should take precedence over when it occurs.

- Thoroughly discussing assessment and grading with students, since a primary objective of education is to have students become self-evaluating.

Researchers indicated that a system based on SBG principles with updated grading methods are necessary in order to achieve "assessment for learning" (Scriffiny, 2008; R. Stiggins, 2009; Tomlinson, 2001). Guskey (2001) said traditional practices reporting only a single grade for each subject area do not offer enough information to detail student progress. Students ought to be entitled to receive accurate and timely feedback on their strengths, deficiencies, and actions that can be taken to achieve learning goals. Educational standards (Common Core) have become a focus and they seem to bring greater clarity to what students should learn and should be able to do. Research supports feedback relative to standards; Hattie (1992), in a review of studies on learning and instruction, reported that providing students with specific information about their standing in terms of particular objectives significantly increased their achievement. Studies have shown that standards-based teaching practices correlate to higher academic achievement (Craig, 2011; Schoen, Cebulla, Finn, \& Fi, 2003). Therefore, it is critical that teachers also link assessments and reporting to the standards (Guskey, 2001).

\section{Research Methods}

This study used qualitative methods to investigate the research questions. To best answer the research questions, the researchers used purposive sampling. The target population was parents who have expressed displeasure with the SGB system that the school uses. In conversations with the building principal, parents were identified who have both expressed concerns with SBG and who were open to discussing the topic. The participants were consented via the process approved by the university's institutional review board (IRB). Participant interviews were digitally recorded and transcribed by the researchers. Participants were asked open-ended semi-structured questions in interviews that lasted approximately one hour. To ensure anonymity pseudonyms were used for all people and places in this study. Participants were informed they could withdraw from the study at any time without penalty. Triangulation occurred via the participant interviews, a detailed researcher's notes/journal and document analysis of district literature (grading policies) and the reporting process (online grading software).

\subsection{Data Analysis}

While reading the transcripts, the researcher horizontalized the data by noting any key phrases or sentences that stood out as particularly meaningful or descriptive. Examples include, "As long as it's an S then he doesn't care," "It's really more of a lax attitude for the student," and "It just seems like there's just not like a lot of accountability." Categories were used as a structural code in order to address the research question: What are the experiences of parents with no teacher preparation or training in interpreting standards-based grading? Breaking down the participants' experiences into categories allowed the researchers to deductively identify which aspect of the process of interpreting standards-based grades the participant was discussing. After providing a structural code, the researchers provided a descriptive sub-code based on the topic being discussed. Example sub-codes include topics such as timing, understanding ability, Power School, standardized tests, and redos/retakes.

Emotion coding with descriptive sub-coding was used in order to address the research questions "How do parents feel about the shift from traditional to standards-based grades (emotions)?" and "What do parents find helpful or problematic about interpreting standards-based grades?" The rationale for using emotion coding was that it revealed the participants' perspective on the experience (Miles, Huberman, \& Saldaña, 2014). By identifying an emotion, the researcher was be able to determine which areas create feelings of difficulty (frustrated, confused, unclear, etc.) or ease (confident, informed, 
excited, etc.) in regard to the research questions. Examples of this include "Confused: Conferences" and "Confused: Communication." When possible, direct quotations from the participant's speech regarding emotions were used, such as "I'm just confused" or "It's just really frustrating as a parent" (Miles, Huberman, \& Saldaña, 2014).

\section{Results}

The participants in this study generally had good experiences in school and all did well when they were students in school. Each parent, at some point, had expressed their concern over SBG with a school official. The participants were chosen because of their frustration with SBG and each participant seemed eager to share their experiences and willingly participated in the interviews.

Jessica has three children that attend school in this district. As a student, Jessica recalls having had good experiences throughout her schooling and described herself as "studious". She went to a small school (15 students in her grade) in a different state and received good grades. Jessica's mother was an elementary teacher, and her mother's high expectations, along with the fact Jessica was "driven" contributed to her success in school. As a parent, Jessica expects her three children to do well in school.

Melissa went to school on the east coast and generally liked school. She did well in school and although she graduated among the top students in her class, she believes she could have done even better if she wasn't involved in so many extra-curricular activities. Melissa has two children that go to school in the district--both middle school. She thinks her oldest student isn't being pushed and that SBG encourages students to just become "secure" as opposed to advancing beyond that level of proficiency.

Nicole has five kids in the district ranging from grade three to 12. Nicole went to school in Kansas in a small town. Nicole describes her school experience as "neutral". "I was more social than studious," she recalled. She laughs about a time where her algebra teacher have her a good grade (she said she struggled in this class) and the teacher said it was a "gift" because she really wasn't getting it. Now, as a parent, she describes herself as "hardcore" and expects her kids to try hard and get good grades.

\subsection{Confidence in the Known, Dislike for the Unknown}

The overarching idea unanimously present in each interview was a preference for traditional grading over standards-based grades. Overall, parents spoke about traditional grading with a sense of confidence in its accuracy. Nicole claimed it was "a clearer snapshot of how he's doing" and made them feel "like I can really tangibly see what's happening there". Parents attributed this confidence to the quantitative nature of traditional grading. For example, Nicole explained, "It's got a quantitative number that's kind of there as a summary and I'm not having to decipher all those kinds of statements." Jessica echoed with, "There's just no guessing." Parents felt that the single numerical grade provided clarity and ease of interpretation because "it's concrete" (Nicole). They felt strongly that a letter grade gave a clear description of their student's level of understanding; "As a parent [I] like the grading system because I can tell, you know, if, if they make an A on those normally they've, um, done a lot of, you know, studying and they understand it" (Melissa).

Confidence in traditional reporting tools also surfaced in terms of standardized testing. When asked how they knew if their students were doing well or struggling, all parents immediately discussed standardized test scores. Jessica openly acknowledged, "I don't look at the grades. I look at their [standardized] tests." Standardized test scores were seen as an easy and reliable tool in order to determine student ability; "I always found their MAP, the MAP test and the Iowa Test of Basic Skills kind of helpful" (Nicole). Jessica explained how she uses standardized tests as a black and white comparison tool:

It's comparing with all the kids in his district, in his grade, and nationally and he only took the test once. So it tells me did you know the material or did you not? And how are you comparing with the rest of the kids?

Parents expressed that standardized tests provided a concrete number in additional to traditional numerical grades that they felt clearly measured understanding.

In contrast, parents spoke about standards-based grades with much less assurance. They felt less confident in interpreting their student's progress in a standards-based system due to what they saw as a lack of precision. Nicole discussed seeing a traditional grade as being a "measurement" compared to, in her words, the "subjectivity" standards-based grading:

I just don't feel like there's a real good metric in place. And I'm sure that there probably is behind the scenes or something but some of it I feel is just, I mean, to me I don't know what that really means. Like, there's not a measurement on it. It's, I don't know. Like a number helps me better understand.

Parents were much less confident in their ability to determine where their students were at with the new grading system. "It's just more general, ya know," claimed Jessica. "If they have a grasp of it they're going to get an S." For this reason, 
parents did not find standards-based grades as illuminating in terms of their students' progress. "It's really confusing to me as a parent," explained Melissa.

In addition to the "wishy washy" (Nicole) characterization of standards-based grades, parents also compared traditional and standards-based grades in terms of pride. Parents described traditional grades with a sense of honor and saw standards-based grades as "irrelevant" (Jessica). Jessica said the memory about grades that stood out most to her during her educational experience was opening your report card at the end of the term and seeing the grade she ended up receiving. Melissa described a similar sense of pride and anticipation: "If you come home and you make an A or you make straight A's everybody's jumping up for joy." All parents spoke of traditional letter grades and grade point averages as a competitive label to determine who they were as a student. For example, Jessica claimed, "I cared a lot about school... one of those A/B students." Nicole also defined herself by her grades: "I got good grades. Um, like probably I think I had over a 3.5 when I graduated so that would mean I was a good student." Parents directly connected being a "good student" with a traditional grade that made them proud.

While parents saw traditional grades as a competitive badge of honor, they described SBG differently. Parents saw a lack of competition and sense of achievement as a negative. For example, Nicole described it as an "everybody gets a medal kind of thing" where "you don't want to hurt somebody else's feelings." Parents did not like this approach and described standards-based grading as being void of competition in order to ensure "a better feeling for them in class" (Melissa) because "it keeps everyone on a more level playing field so kids can't pick on other kids because they're getting lower grades" (Jessica). Parents did not like the idea that "everyone's the same" (Nicole) because they felt it took away from the sense of achievement they associated with traditional grades. They felt it was unclear in a standards-based system whether or not the student had earned something to be proud of. All parents felt that an A had meaning whereas in standards-based grading “it's just an S" (Jessica).

Parent responses presented a clear dichotomy separating their attitudes toward traditional and SBG. They spoke with certainty in regard to numerical reporting and aversion to what they perceived as a nebulous system of SBG. This evidence led to the theme of confidence in the known and a dislike for the unknown.

\subsection{Poor Communication Leading to Disappointment}

The second theme that emerged from the interviews was a sense of poor communication from the school to the shareholders. Parents felt that their voice was not being heard, which then led them to disengage from the communication process.

This lack of parent voice was first discussed in regard to the district's decision to implement standards-based grading at the sixth and seventh grade level. Parents who had students in the district during the decision to switch grading systems did not feel that there was two way communication giving parents a say in the ruling. For example, Nicole said, "I just didn't feel like the parents really had very much voice in it... like the parents really had the power to, like, to really impact it." The feeling of being ignored was exacerbated by the fact that parents felt the decision had already been made. Jessica explained, "From what I had heard, the school had pretty strongly already made up its mind that they were going to do it." Parents described a feeling of powerlessness in regard to the situation: "I really, I felt like the decision was made. I didn't feel like anything was going to change it" (Nicole).

Feeling as if change was futile led to parents giving up on the situation. While they felt "disappointed" (Jessica), they felt that "it is what it is" (Nicole) and that any attempt to challenge the decision would pointless. Jessica explained, "I'm not going to waste any energy or time in worrying about a decision that's already been made if it's already done." Parents felt that communicating their concerns was useless. They felt the district had an agenda and would move forward with or without their support.

Open communication was lacking not only during the decision-making process but also suffered during implementation of the new grading model. "I don't feel like I got a whole lot of information from the school," remembered Nicole in regard to the switch. "I was hearing more things from other people and not a whole lot from the school." Parents also did not feel they received a clear description of the process; "I don't remember seeing a big explanation" (Melissa).

This lack of communication applied not only to the initial implementation year but also subsequent school years. Parents claimed they were not receiving adequate information from administration regarding the system being used at each grade level. Melissa moved to the school district a year after implementation and was completely unaware that they were using a standards-based grading system. She shared, “To be honest, when we moved here I didn't realize that they were doing that" and that it was "a couple months of being in the school system before I realized." Melisssa also did not know that students switched to traditional grading in eighth grade until it came up in our interview. Her frustration with the lack of communication was apparent in her response: "See and I didn't even know that! [surprised/angry tone] So why don't I 
know that?" Parents did not feel they were getting regular communication or explanation from the administration in regard to SBG practices being implemented with their children.

Communication shortage between the school and parents is not only limited to the administration. Parents unanimously discussed their frustration with the responses they receive from teachers at conferences. They described a "lax attitude when it comes to conferences" that feels "like I was going in a circle" (Melissa). Nicole said:

I feel like it's a tape recording for all the kinds so far. Um, sometimes I feel like, 'Do you even know him? Do you even know him?' kind of. It, it feels very impersonal to me."

Conversely, parents felt conferences are detached and pointless. Jessica commented:

Every conference I've gone to they're like 'Oh yea, everything's good. Everything's fine. Do you have any questions?' Um, and that's been the extent of it. I mean, I continue to go because I want my child to think that, um, I care, because I do care, but I get very little out of conferences.

Melissa seemed to share a similar perspective about conferences:

I told [the Associate Principal] about that. I said, 'You know, I'm kind of, what do I need to do?' And he basically said well figure out where, you know, she needs help. I don't mean to be ugly but it just seemed like that was not a good answer either. It just seems like there's just not a lot of accountability... I guess it's all on us.

Conferences were described as disappointing and uninformative. Jessica argued, "A few teachers you know once in awhile give a little bit of input. It's usually pretty vague... I don't know that that's valuable either." Parent responses showed a desire for quality, personalized communication regarding their students' progress. However, they did not feel these needs are being met. Thus, attending conferences appeared to be more of a symbolic act rather than a means of accountability and communication.

Gaps in communication regarding standards-based grading and conferences impacted parents' level of engagement with the school. Parents felt unheard regarding the switch to the new grading system, and now they feel they do not have the information they need to understand their student's learning. Jessica reflected on how communication impacted her relationship with the school:

On a very subconscious level I have less interest...At the end of the school year I never check it because I know

they pass them on, and my child doesn't care if they got a D or an S, so there they really become irrelevant.

Melissa echoed her claim in regard to student progress; "I just don't get too excited about looking." While parents noted that they don't necessarily feel the lack of communication is enough to leave the district, they felt it impacted their level of engagement with their students' learning. Jessica said, "I'm not going to move across town because of the grading system" while Nicole explained, "I don't really feel like the value of education has gone down. I just feel like I don't have as pretty of a picture of where my child is at as I did before."

An overwhelming theme across each interview was the fact that poor communication led to disappointment and disengagement amongst parents. Parents did not feel that they received adequate information regarding the shift from traditional to standards-based grading, and they felt that face-to-face communication at conferences lacked depth and that their questions remained unanswered. Thus, parents felt less connected to the school.

\subsection{Confusion from Lack of Clarity}

Two predominant emotions surfaced across all interviews. All parents expressed feeling unclear and confused in regard to the current grading system. Parents described the process of interpreting a standards-based report card and highlighted multiple areas where they felt uncertain and thus confused in regard to how to interpret their students' learning.

The area most commonly discussed was the range of proficiency indicators. Parents felt that there was a "broad" or "wide" range to what each proficiency indicator in Power School really meant (Jessica). Each parent gave their own interpretation of how they compare a proficiency indicator (beginning/developing/secure/exceeds) in standards-based grading to a traditional letter grade $(\mathrm{A} / \mathrm{B} / \mathrm{C} / \mathrm{D} / \mathrm{F})$, with each parent giving a very different response. However, all parents shared that they did not know exactly how to interpret a proficiency indicator. For example, Jessica's confusion was, "To me an $\mathrm{S}$ could be anywhere from a C- to an A, which I think is a pretty broad range," and Nicole described it as being "subjective" in a way that she "can't really get a feel for what's really happening." Parents shared that with this wide range for indicator comes uncertainty as to what a proficiency indicator means in terms of student learning. Nicole explained her confusion with interpreting the meaning behind a "developing" proficiency indicator; "When you just kind of tell me they're developing it's like, it's like I don't really know what that means. It's, 'So he's okay...?'” This applies to both struggling and advanced learning as Melissa saw the same confusion with an "exceeds" indicator; "To me if you went exceeds, and see that's another thing to me that's confusing is, you know, exceeds, okay so she exceeds. So where does that mean?" 
Parents frequently described asking themselves "But what does that really mean?" (Nicole) as they looked through Power School.

In addition to the "broad" range of proficiency indicators, parents expressed confusion in regard to the timing of those indicators. Parents had been told that students have the entire year to become secure in a standard. Therefore, parents were unclear when they saw a "developing" during first semester in Power School. They did not know if it meant that the student did not understand the material or if they understood what was expected at that point in the school year, but not yet the whole standard as there was more learning yet to come. Jessica said:

So you're not even really sure is the D meaning they understand, they're doing really well [questioning voice], or they're not doing well but they're not expected to do well because it's the beginning of the school year. So there's a, there's kind of a big difference in that area to me.

Melissa said:

From what I understand is that really, and this is the most thing that is very confusing as a parent about this type of grading, is that they need to be at secure by the end of the year. So if they're learning something new in the fall I'm not going to be as worried about it.

The lack of clarity in regard to timing of proficiency indicators created confusion. Parents felt that there was no clear differentiation between what has not been learned because of a struggle by their individual student versus what has not been learned due to the timing of the curriculum.

Parents' confusion regarding how to interpret proficiency indicators may have stemmed from their lack of clarity regarding teachers' decision making. Parents felt they did not know how the teacher came to the decision that a student was beginning, developing, or secure. For example, Nicole asked herself, "How did the teacher evaluate that this is a developing or how is she evaluating it at secure? Or how did the German teacher decide that he's exceeding that in German?" These parents did not have a strong background in interpreting rubrics. Two of the parents did not know what they were when asked by the interviewer. Nicole described trying to interpret a rubric with her son; "I was kind of like, "Huh?"' Because parents were unclear in deciphering standards-based grading rubrics, they did not understand the decision-making process of teachers. When asked by the interviewer how she knew what assignments or materials led the teacher to their grading decision, Jessica responded that she "had no idea." Parents felt this confusion stemmed from the way standards-based grades are posted in Power School compared to traditional grades. Jessica said:

You just kind of see like that she's at developing at a particular area. So, you can't like drill in and see okay the assignment associated with that, or, um, the test or the quizzes associated with that or the activities associated with that, what they might be putting that value on. You can't see, you can't see where it's coming from, basically.

Interpreting rubric-based decisions is not the only area in which parents expressed confusion in regard to Power School. Parents did not feel that Power School gave them enough of the information they need to interpret student progress. For example, Tamara claimed she "doesn't see it as much of a tool." One of the critiques of Power School is that there is too much information to "sort through" and "decipher" that it becomes "overwhelming" (Nicole). Nicole described the experience of going online:

You're scrolling, it's, it's not absorbing and you're just sitting there like 'Huh?'.... It's kind of like when you get an email or a letter and it's, there's so much text in it you just kinda glaze over a little bit and that's kinda how I feel.

Not only is there a significant amount of information, parents do not feel that the information provided is informative or useful. Melissa claimed, "It doesn't give a lot of information. It seems to be a very broad, um, synopsis." Parents felt the standards-based objectives provided are too broad to truly understand what students are learning; "I know, I know there's, you know, maybe 8 or 10 different things but there's got to be a lot more than that that they're learning in the class I would think" (Melissa). Because they did not see Power School as revealing, they did not use it frequently. None of the parents interviewed reported using Power School on a regular basis. For example, Melissa said, "I don't look at it routinely" and Nicole admits, "I'm kind of guilty of glossing over it." Parents all described themselves as being busy and therefore not seeing Power School as an informative use of their time. Jessica explained, "I'm busy and checking Power School is another thing to do and it's not going to give me a whole lot of information." Because standards-based grades are unclear and confusing on Power School, parents did not see the grade reporting method as a tool to understand student learning.

Due to a lack of clarity regarding the range and timing of indicators, rubrics, and navigating Power School, parents expressed confusion and difficulty understanding their student's ability. Because they did not understand how decisions are being made or the method of communication, they felt they "don't have a good grasp like really where his strengths 
are" (Nicole). Jessica felt like she's "just assuming what it means in [her] mind." Melissa related this confusion to her understanding her child's future; "I think it confuses me on what their potential could be." By not knowing where their students are in their learning, parents did not know their student's true abilities. This led to the theme of confusion from lack of clarity. Because parents did not feel they have received a clear explanation of standards-based grade reporting, such as how to interpret timing or range of indicators, how decisions are made based on rubrics, or to navigate Power School, parents were left confused. Melissa summed up the impact of this confusion on her opinion of standards-based grading; "Maybe the, um, the secure and developing would give me a better understanding of where she is versus the A, B, $\mathrm{C}$ and D's in the long run. But I think... I don't really understand it and I don't really have enough information it."

\subsection{Frustration Due to Perceived Outcomes}

Another emotion that parents overwhelmingly described experiencing was a sense of frustration. Because they felt uncertain and confused regarding standards-based grading, they found themselves frustrated with the results they feel they see in their students. Parents felt their expectations differ from those of the school regarding students' their sense of responsibility and motivation. Parents blamed the frustrating outcomes they are observing in their students on standards-based grading policies.

Parents were concerned that the redo/retake policy and no penalty for late work in standards-based grading creates a "false" sense of reality (Jessica). Parents strongly valued accountability and consequences, but they felt these policies were lacking in those areas. Melissa said:

I don't think it's holding the kid accountable. I think it just makes them like not be accountable for what they, there should be some consequence if they're not doing, they're not turning their work in at the right time.

Parents felt that their students were not taking the time to do their best on homework or tests the first time around. Jessica explained that for her son, "The first time if he has something else going on in his life he doesn't take it very seriously." Parents felt that because there are no consequences, students feel no need to work hard the first time; "You know that you're not going to be accountable for what, you know, you do on it, so what drives her to really do the best she can do the first time?" (Melissa). While their students may be fine with redos and late work, parents were not. For example, Nicole shared that "Jake has a couple of missing assignments as we speak. And, and I'm not okay with that." Jessica claimed that with this system "the kids are not held responsible to be respectful and do things on time" and Melissa echoed, "They should have some consequences." Parents felt that by allowing redos/retakes and no giving any penalties for homework, their students did not have a sense of responsibility or accountability for their work.

In addition to being frustrated with a lack of dependability on the part of their students, parents were discouraged by the lack of pride they saw in their students. They claimed their students were no longer motivated to push themselves to work harder and achieve more. "It has definitely dropped his motivation a ton," claimed Jessica. "As long as he has an S he is totally fine with that." Parents felt that their children were not being pushed to reach their true potential and were settling with a secure rather than being challenged by their teachers to meet the "exceeds" level. For example, "He knows all he has to do is get an S. That's good enough" (Jessica). Melissa explained that she wants her student to be challenged to achieve more; "If she is secure I want her to be pushed toward the exceeds." Parents felt that this lack of student motivation was due to a lack of pride in their work. Nicole said that her son said " "Hey I got a biology test and I got an 89 on it or I got a 92!' I mean he doesn't come home and say, 'I got a secure on this unit or this skill or this..."'

Parents seemed to think the mindset of the school is that a "secure" is expected rather than a source of accomplishment. According to Jessica, "As long as you turn in your work, you do barely what you need to do, you get an S." She claimed, "It's teaching him that's good enough. He just puts in the minimum." Melissa described it as "more of a lax attitude for the student" where the child's level of motivation ultimately determines how much effort is put into an assignment. Jessica said:

And it gets kind of late at night and he gets tired and he's like, 'Well I'm just gonna quit doing it because if I don't pass the test then the teacher will just have me come in and retake the test or retake the assignment' or 'I elected to do the exceeds but I'm just going to drop down to the secure because that's all that's expected of us."'

Rather than students deciding on the level of expectations, parents wanted their children to be challenged by the teacher. Parents felt that their personal expectations for their student are different than those of the school. Jessica claimed, "How my son views grades are way different than how I view grades." Parents felt as though the school lets lower expectations for student learning are set lower than they would like as a parent. Melissa explained:

I feel like, like Jillian can do a lot more than she's doing and I feel like that she's not being pushed.... Most of my frustration is I don't feel like she's being challenged in the areas I think she needs to be challenged in. Jessica also saw a difference in level of expectations as she explains analyzing her student's work and disagreeing with the teacher's assessment; “There was so little effort put forward that I didn't really feel like it was always secure 
work." She felt teachers have the mindset that "it's just about getting the whole group to that S." Based on their observations, parents saw SBG policies having negative effects on their student's level of self-motivation and challenge.

Because parents were frustrated and felt their expectations for their students were different from the school, parents were worried about their children's futures. All parents' comments showed that they placed a strong emphasis on traditional grades because they felt that they "counted" more toward their student's future compared to standards-based grades. For example, Melissa was concerned that in "ninth grade the college stuff does start counting and stuff," while Nicole felt that "they need the exposure and kind of the practice of giving a real grade before it becomes for real." Because they did not see standards-based grades as "real grades," all parents expressed concern for how the outcomes of standards-based grading practices will impact their students' work habits in high school and beyond. For example, Melissa felt her daughter is "being limited" by the practices and did not want it to impact her college prospects:

I think that's a false, um, reality of what the high school's going to be like what the real world's going to be like, that they can just keep doing the job or whatever until they, they get their raise just because everybody else is going to get the raise for example. It's not that way. You know when you're working on a job and have to do what you have to do and you're gonna have deadlines and you're going to have to complete jobs and you don't get that, that type of, um, a flexibility in real life and I think that's what school is also, you know, life learning.

Parents worried that SBG practices will impact their student not only during middle school but in the future.

Because they felt their students have less responsibility and motivation, parents were dissatisfied with what they see as a difference in expectations. Jessica went as far as to claim it makes her "fearful of the generation we have coming up." Not only were parents frustrated with their student's current behaviors, they feared standards-based practices are having long-term impacts on their children.

\section{Discussion}

Data from these interviews produced five themes: Confidence in the known, dislike for the unknown; poor communication leading to disappointment; confusion from lack of clarity; and frustration due to perceived outcomes. Parents felt confident about traditional grading practices, yet questioned standards-based grading. They felt they had not received adequate communication both during the decision to switch to standards-based grading and in its implementation phase. Parents were also dissatisfied with ongoing communication during conferences, which causes them to feel less engaged in their children's education. Due to lack of communication, parents were unclear and thus confused regarding standards-based grading practices such as proficiency indicators, rubrics, and navigating Power School. Parents also thought standards-based grading practices were having a negative influence on their students' behavior, causing them to have less responsibility, pride, and motivation. These perceived outcomes frustrated parents and caused concern for their student's future.

If report cards are to provide the parent and student with necessary information regarding the student's learning, then the parents' needs and desires should be considered when implementing an alternative grading practice. According to Goodwin (2003) "Parents and students are a crucial yet often missing part of most accountability systems... thus, educators and policymakers would be wise to sit down with their publics and engage them in genuine dialogue about their schools" (p. 3). Parents must be included as stakeholders in the conversation around the purpose of grades and reform prior to any steps being taken.

Much of the aversion to SBG by parents appears to relate to the long-standing use of, and familiarity with, traditional letter grades and perhaps simply anxiety about the unknown (Peter Peters \& Buckmiller, 2015). Most everyone taking part in the transition to SBG - teachers, parents, administrators, and board members - is a product of traditional grading methods. As Brookhart (2011) has noted, schools attempting to alter their grading systems must deal with stakeholders' beliefs, long-standing habits and experiences, not only concerning grading but also learning, discipline, and classroom management.

Certain school decisions require community participation and involvement and should be informed by multiple stakeholders, including parents. The decision to shift grading systems is one that must be made purposefully and should involve intentional means of communication, dialogue and development for all involved. Reframing the purpose of grading toward student learning via standards-based grading may require a significant shift in parents' schema. The more positive experiences a parent has with the school, the greater their level of trust and support, and thus the greater support for a new grading model. Therefore, positive school-parent relationships via communication are key to increased acceptance of standards-based grading.

Parents interviewed in this study described a number of frustrations, which were essentially barriers to the successful full implementation of SBG at this school. The parents' interpretation of "grades" included only traditional grades and 
standardized assessment. Thus, they had difficulty adjusting their schema to the rules of SBG. This resulted in increased expression of confusion and frustration with the new model. School leaders and classroom teachers must anticipate these issues and proactively confront them. They are largely unavoidable challenges that must be met head-on, with thoughtful, well-reasoned, and practical strategies (Guskey, 2011). Teachers must have a crystal clear understanding of the purposes of assessment and how assessment is aligned with pedagogy in their classroom and they must be able to communicate their assessment strategies in a way that is rational, focused, and that invites a thoughtful dialogue around the topic.

The implementation dip is another aspect of transitioning to standards-based grading and reporting that must be anticipated. Because SBG replaces a process that is the only one most stakeholders have ever known, many interviewees cited a number of changes that elicited unintended initial effects. For example, because SBG de-emphasizes graded, scored homework in favor of formative feedback, parents and students often conclude that homework was no longer important. Ongoing formative practice and assessment is a critical component of SBG and it will take time for stakeholders to reframe their perception away from 'what is important is what is graded.' Additionally parents are often uncomfortable with the practice of allowing re-submission of work and retakes of tests and quizzes. In these cases, teachers generally find appropriate alternatives that allow students to redo critical work and demonstrate their most current level of proficiency.

This study highlighted a typical technological challenge to effective and comprehensive standards-based reporting in that many grading software information systems have not yet sufficiently evolved to accommodate SBG. Peters and Buckmiller's (2014) study confirms that information and grading systems are significant impediments, largely because the most available and commonly used programs continue to use points and percentages to calculate and report grades. This method contradicts the purposes of standards-based report, which avoids accumulating points on a percentage scale in favor of formative feedback, most recent assessment of student achievement, and four point rubrics aligned with learning targets (Peters \& Buckmiller, 2014)

The implementation of SBG is a difficult endeavor, even in school districts that tend to be progressive in their educational approaches. In order to enhance the likelihood of implication success, ongoing professional development and collaboration, and effective two-way communication about the purpose of grading is needed and should be facilitated by school leaders and classroom teachers. Actively taking part in the discussions and practice surrounding SBG appears to require a growth-mindset, a disposition that holds great potential to engage both students' intellect and motivation. Ultimately, successful transition to SBG must involve teachers and leaders who build and communicate a sense of urgency and focus around the critical objectives of education which advocate for the skills and dispositions for lifelong learning into adulthood and having ongoing, constructive conversations about learning and growth in collaboration with others.

\section{References}

Brookhart, S. M. (2011). Starting the conversation about grading. Educational Leadership, 10-14.

Connor, K. O., \& Wormeli, R. (2011). Reporting student learning. Educational Leadership, 40- 44.

Craig, T. A. (2011). Effects of standards-based report cards on student learning.

Frye, A. W., \& Hemmer, P. A. (2012). Program evaluation models and related theories: AMEE Guide No. 67. Medical Teacher, 34(5), e288-e299.

Goodwin, B. (2003). Digging deeper: Where does the public stand on standards-based education? Mid-continent Research for Education and Learning, (July).

Guskey, T. R. (1994). Making the grade: What benefits students? Educational Leadership, 14-20.

Guskey, T. (2001). Helping standards make the grade. Educational Leadership, 59(1), 20-27

Guskey, T. R. (2011). Five obstacles to grading reform. Educational Leadership, 17-21.

Hattie, J. A. (1992). Self-concept. Hillsdale, NJ: Lawrence Erlbaum.

Lubienski, S. T. (2004). Traditional or standards-based mathematics? The choices of students and parents in one district. Journal of Curriculum and Supervision, 19(4), 338.

Marzano, R. J., \& Heflebower, T. (2011). Grades that show what students know. Educational Leadership, 34-39.

Marzano, R. (2000). Transforming classroom grading. Alexandria, VA: ASCD.

McTighe, J. (1997). What happens between assessments? Educational Leadership, 54(4), 7-12.

Miles, M. B., Huberman, A. M., \& Saldana, J. (2014). Qualitative data analysis: A methods sourcebook (3 ${ }^{\text {rd }}$ ed.). Los Angeles, CA: Sage. 
Munk, D. D., \& Bursuck, W. D. (2001). What report cards should and do communicate. Remedial and Special Education, 22(5), 280-287.

O'Connor, K. (1999). The mindful school: How to grade for learning. Arlington Heights, IL: Skylight Professional Development.

Peters, R., \& Buckmiller, T. (2014). Our grades were broken: Overcoming the barriers to implementing standards-based grading. Journal of Educational Leadership in Action, 2(2).

Peters, R. and Buckmiller, T. (in press). Understanding the school leader's role in

implementing standards-based grading. In L. Hollingworth (Eds.) Organization and administration of Iowa public and private schools (second edition). Dubuque, IA: Kendall Hunt Publishing Company

Popham, W. J., \& Husek, T. R. (1969). Criterion-referenced measurement. Journal of Educational Measurement, 6(1), 19.

Reeves, D. B. (2011). Taking the grading conversation public. Educational Leadership, 76-79.

Reeves, D. (2004). The case against the zero. Phi Delta Kappan, 324-325.

Schoen, H. L., Cebulla, K. J., Finn, K. F., \& Fi, C. (2003). Teacher variables that relate to student achievement when using a standards-based curriculum. National Council of Teachers of Mathematics, 34(3), 228-259.

Scott, S. (2005). What's in a grade Scott. General Music Today, 18(2), 17-24.

Scriffiny, P. L. (2008). Seven reasons for grading. Educational Leadership, (October), 70-75.

Stiggins, R. J. (1991). Facing the challenges of a new era of educational assessment. Applied Measurement in Education, 4(4), 263-273.

Stiggins, R. (2005). From formative assessment to assessment for learning: A path to success in standards-based schools. Phi Delta Kappan International, 87(4), 324-328.

Stiggins, R. (2009). Assessment upper elementary FOR learning grades in students learn more when they by Rick Stiggins. The Phi Delta Kappan, 90(6), 419-421.

Stufflebeam, D. (1971). The relevance of the CIPP evaluation model for educational accountability. Paper presented at the Annual meeting of the American Association of School Administrators, Ohio State University, New Jersey (1-30).

Stufflebeam, D. (2003). The CIPP model for evaluation. International Handbook of Educational Evaluation: Kluwer International Handbooks of Education, 31-62.

Stufflebeam, D. (2004). The 21st-century CIPP model: Origins, development, and use. Evaluation Roots: Tracing Theorists' Views and Influences. Thousand Oaks: SAGE Publications, Inc., 243-266.

Stufflebeam, D., \& Shinkfield, A. (2007). Daniel Stufflebeam's CIPP model for evaluation: An improvement/accountability approach. Evaluation Theory, Models, and Applications. San Francisco: Jossey-Bass, 325-366.

Tomlinson, C. A. (2000). Reconcilable differences? Standards-based teaching and differentiation. Educational Leadership, 58(1), 6-11.

Tomlinson, C. A. (2001). Grading for success. Educational Leadership, 12-15.

Wormeli, R. (2006). Accountability: Teaching through assessment and feedback, not grading. American Secondary Education, 34(3), 14-28.

Wormeli, R. (2011). Redos and retakes done right. Educational Leadership, 22-26.

\section{(cc) $\mathrm{BY}$}

This work is licensed under a Creative Commons Attribution 3.0 License. 